\title{
Early infection control
}

The College has always been called on to provide advice on public health. The Sibbald Library exhibition that accompanied the February 2012 RCPE Infectious Diseases Symposium featured Minutes detailing the College's early involvement in infection control.

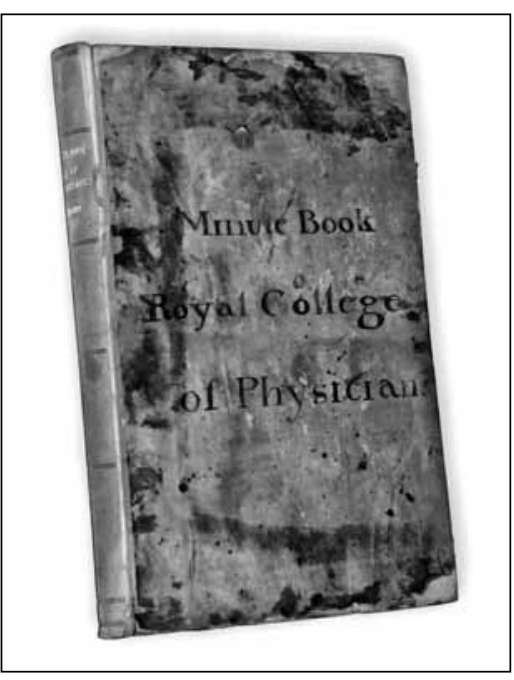

FIGURE I Minute book of the RCPE (1795-1819).

In I72I the Edinburgh Town Council approached the College 'Desyreing the Colledge their opinion and advyce to Guard against any Pestilentious Infection'.

The College appointed a Committee and its recommendations were presented by the President, Dr James Forrest. The Committee advised the draining of the North Loch, leaving a canal in the middle with a constant current of running water from the fountains, removal of the slaughter houses 'to some Convenient distance from the Toun', removal of 'dunghills' and frequent cleaning of the streets. It also recommended waggons to collect 'what is gathered in privat ffamilies... and non to be allowed to throw out any kind of nastiness over windows or in the Staires or closses'.

The College continued to provide advice for the Town Council.

In 1817 the RCPE President, Dr Thomas Hope, received a letter from the Lord Provost with a 'Request, that you will have the goodness to ascertain... the present State of Fever in this city'. The College's reply stressed the importance of 'ventilation, cleanliness, separation of the sick from the healthy, purification of apartments, bedding and Clothes etc'. 'The Royal College have therefore no hesitation on declaring that they consider it of great consequence to the health of the Inhabitants, but more particularly of the poorer classes, that no

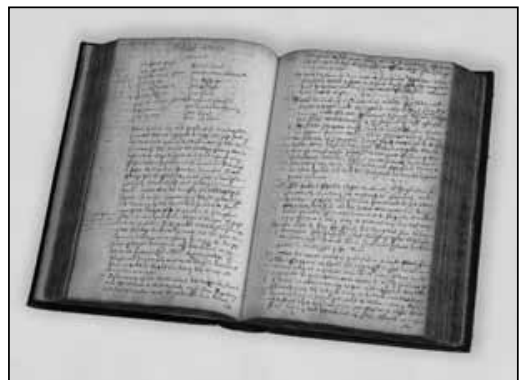

FIGURE 2 College Minutes 31 October 1721.

accumulation of putrescent matter should be formed within the Town or in the immediate vicinity of it'.

In 1843 the College recognised the need for a fever hospital. The Minutes record: 'the Present state of Fever in Edinburgh called loudly for the support of the public in establishing a Fever Hospital.' A formal motion was submitted to the Dean of the Faculty of Advocates with the opinion of the College 'that there should be no further delay...for the erection of an Hospital...for the benefit of the sick and hurt.'

Estela Dukan and lain Milne

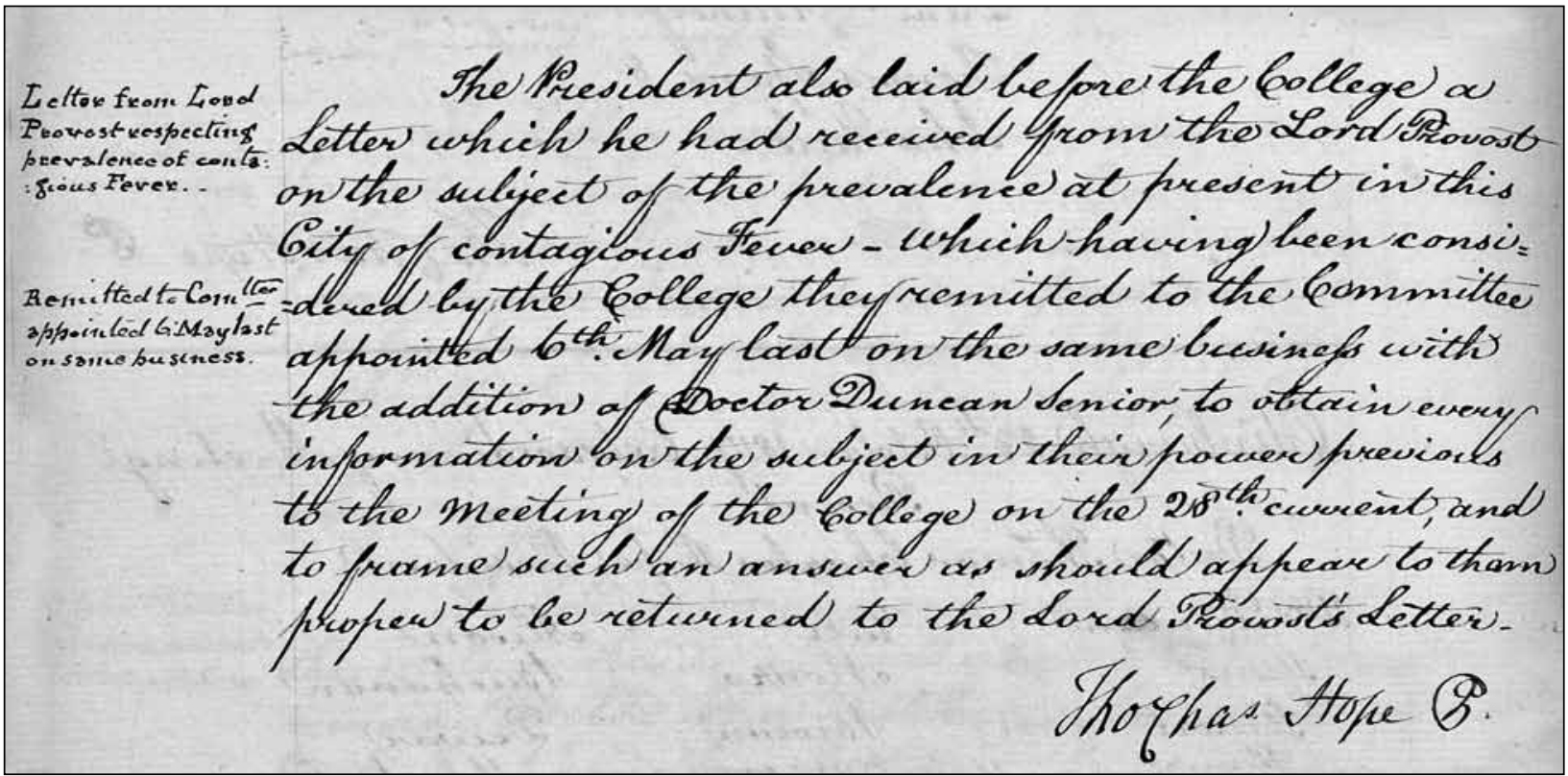

FIGURE 3 College Minutes 23 October 1817. 